\title{
'Lumbar Degenerative Kyphosis' Is Not Byword for Degenerative Sagittal Imbalance : Time to Replace a Misconception
}

\author{
Chang-Hyun Lee, M.D., M.S.c., ${ }^{1}$ Chun Kee Chung, M.D., Ph.D., ${ }^{2,3,4,5}$ Jee-Soo Jang, M.D., Ph.D., ${ }^{6}$ Sung-Min Kim, M.D., Ph.D., \\ Dong-Kyu Chin, M.D., Ph.D., Jung-Kil Lee, M.D., Ph.D., ${ }^{8}$ On behalf of the Korean Spinal Deformity Research Society \\ Department of Neurosurgery, Ilsan Paik Hospital, Inje University College of Medicine, Goyang; Department of Neurosurgery, ${ }^{2}$ Seoul Na- \\ tional University Hospital, Seoul National University College of Medicine, Neuroscience Research Institute, ${ }^{3}$ Seoul National University \\ Medical Research Center, Clinical Research Institute, ${ }^{4}$ Seoul National University Hospital, Department of Brain and Cognitive Sciences, ${ }^{5}$ \\ Seoul National University College of Natural Sciences, Seoul; Department of Neurosurgery, ${ }^{6}$ Nanoori Suwon Hospital, Suwon; Depart- \\ ment of Neurosurgery, Spine Center, Kyung Hee University Hospital at Gangdong, Seoul; Department of Neurosurgery, Spine and Spi- \\ nal Cord Institute, Gangnam Severance Spine Hospital, Yonsei University College of Medicine, Seoul; Department of Neurosurgery, ${ }^{9}$ \\ Chonnam National University Hospital, Chonnam National University Medical School, Gwangju, Korea
}

Lumbar degenerative kyphosis (LDK) is a subgroup of the flat-back syndrome and is most commonly caused by unique life styles, such as a prolonged crouched posture during agricultural work and performing activities of daily living on the floor. Unfortunately, LDK has been used as a byword for degenerative sagittal imbalance, and this sometimes causes confusion. The aim of this review was to evaluate the exact territory of LDK, and to introduce another appropriate term for degenerative sagittal deformity. Unlike what its name suggests, LDK does not only include sagittal balance disorder of the lumbar spine and kyphosis, but also sagittal balance disorder of the whole spine and little lordosis of the lumbar spine. Moreover, this disease is closely related to the occupation of female farmers and an outdated Asian life style. These reasons necessitate a change in the nomenclature of this disorder to prevent misunderstanding. We suggest the name "primary degenerative sagittal imbalance" (PDSI), which encompasses degenerative sagittal misalignments of unknown origin in the whole spine in older-age patients, and is associated with back muscle wasting. LDK may be regarded as a subgroup of PDSI related to an occupation in agriculture. Conservative treatments such as exercise and physiotherapy are recommended as first-line treatments for patients with PDSI, and surgical treatment is considered only if conservative treatments failed. The measurement of spinopelvic parameters for sagittal balance is important prior to deformity corrective surgery. LDK can be considered a subtype of PDSI that is more likely to occur in female farmers, and hence the use of LDK as a global term for all degenerative sagittal imbalance disorders is better avoided. To avoid confusion, we recommend PDSI as a newer, more accurate diagnostic term instead of LDK.

Key Words : Sagittal · Imbalance · Lumbar · Degenerative $\cdot$ Kyphosis · Flat-back.

- Received : July 7, 2016 •Revised : August 20, 2016 •Accepted : September 22, 2016

- Address for reprints : Sung-Min Kim, M.D., Ph.D.

Department of Neurosurgery, Spine Center, Kyung Hee University Hospital at GangDong, Kyung-Hee University School of Medicine, 892 Dongnam-ro, Gangdong-gu, Seoul 05278, Korea

Tel : +82-2-440-6286, Fax : +82-2-440-8404, E-mail : spinekim@khu.ac.kr

This is an Open Access article distributed under the terms of the Creative Commons Attribution Non-Commercial License (http://creativecommons.org/licenses/by-nc/4.0) which permits unrestricted non-commercial use, distribution, and reproduction in any medium, provided the original work is properly cited. 


\section{INTRODUCTION}

Lumbar lordosis is unique to the human spine and develops as an adaptation that facilitates the upright posture. Sagittal spinal alignment with intact sagittal balance enables humans to walk in an upright posture with minimum power ${ }^{19}$. However, decreased lumbar lordosis and increased thoracic kyphosis are hallmarks of an aging human spinal column ${ }^{21}$. Loss of lordosis causes irregular weight distribution on the spine. The resulting increased energy expenditure required to maintain the erect position aggravates back pain and loss of lordosis ${ }^{11}$. The impact of sagittal plane alignment on the treatment of spinal disorders is of critical importance. Failure to recognize malalignment in this plane can have significant consequences for the patient, not only in terms of pain and deformity, but also in terms of decreased social interaction due to deficient forward gaze $\mathrm{e}^{20}$. Awareness of sagittal balance, even when addressing problems in the coronal plane, is necessary to avoid future complications ${ }^{20)}$.

With an aging society, adult degenerative deformity has become one of the most notable topics of spinal disorders owing to its significant impact on health related quality of life ${ }^{24)}$. Lumbar degenerative kyphosis (LDK), a sagittal plane malalignment disease, was first described by Takemitsu et al. ${ }^{23}$, and is caused by unique life styles such as the prolonged crouched posture during agricultural work and performing activities of daily living on the floor, as shown in Fig. $1^{16}$. Previous papers reported that LDK was frequent only in the farming districts of 'oriental' countries such as Korea and Ja$\operatorname{pan}^{14,16,23)}$. Patients with LDK usually show extensive degenerative changes of the lower lumbosacral discs and facet joints from L2 to S1 levels, and atrophy and fatty changes of the lumbar extensor muscles ${ }^{16)}$. LDK has been the subject of numerous publications in Korea and Japan; however, meaningful progress toward understanding the pathogenesis of this disease has been limited ${ }^{14,16,23)}$.

Although the life style of these countries has changed to be similar to that of western countries, the number of patients with LDK in Korea and Japan has not decreased. In fact, the incidence of diseases mimicking LDK has recently been increasing in western countries ${ }^{1,3,8,12)}$. With a rising prevalence, adult degenerative sagittal deformity is emerging as a major health care issue of the 21 st century ${ }^{3}$. This increase cannot be directly attributed to the long hours spent in the crouched

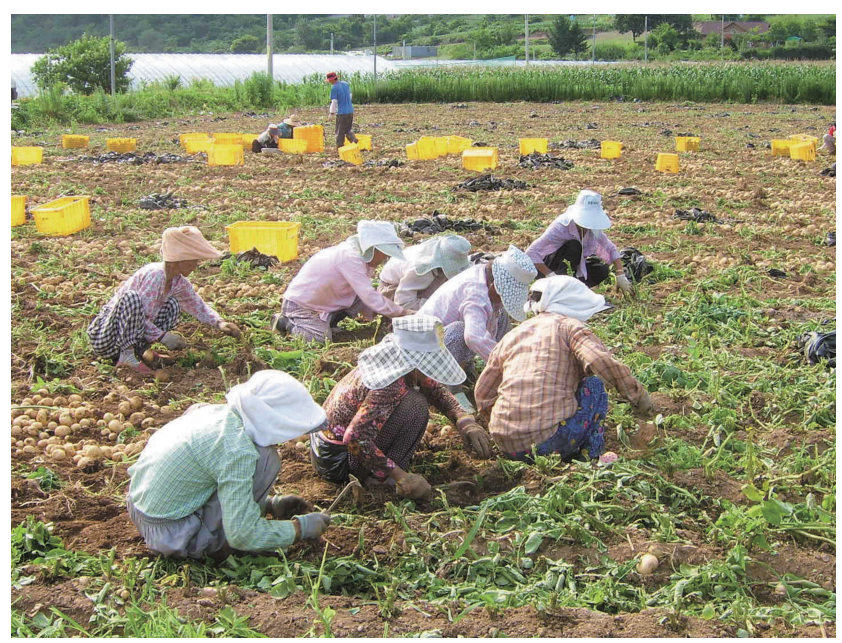

Fig. 1. A photograph showing female farmers working in a crouched posture on the ground in a farming district in Korea. This photograph is courtesy of Korea Agency of education, promotion and information service in food, agriculture, forestry and fisheries.

posture while performing agricultural work, but rather to the increase in the number of elderly patients and other sagittal imbalance diseases. Unfortunately, LDK has been used as synonym for degenerative sagittal imbalance, sometimes resulting in confusion. The aim of this review was to evaluate the exact territory of LDK and to introduce another appropriate term for degenerative sagittal deformity.

\section{'Lumbar degenerative kyphosis' : Is it a misnomer?}

In 1988, Takemitsu et al. introduced the name "lumbar degenerative kyphosis" which included kyphosis or a marked loss of lordosis in the lumbar spine caused by degenerative changes in the middle-aged and elderly ${ }^{23)}$. Unlike what its name suggests, "lumbar" of LDK does not clearly explain the disease entity because the sagittal balance of the thoracic spine is also included in the diagnostic criteria. Takemitsu and colleagues divided LDK into four types by spinal curvatures as shown in Table 1. The detailed description of each type of LDK does not encompass the lumbar spine only, but also the thoracic spine. Moreover, the illustration of LDK types by Takemitsu et al. showed sagittal alignment of the whole spine as depicted in Fig. $2^{23)}$. The sagittal balance of the thoracic spine is very important in the pathophysiology of degenerative sagittal imbalance because the loss of normal lordosis in the lumbar spine is compensated by the thoracic curve and sacral slope". "Kyphosis" of LDK gives the impression that LDK in- 
Table 1. Types of 'lumbar degenerative kyphosis' by Takemitsu et al. ${ }^{23)}$

\begin{tabular}{lll}
\hline Type & Lumbar spine & \multicolumn{1}{c}{ Thoracic spine } \\
\hline 1 & Little lumbar lordosis & Marked loss of thoracic kyphosis \\
2 & Slight lumbar kyphosis & $\begin{array}{c}\text { Slight lordosis in the thoracic } \\
\text { region }\end{array}$ \\
3 & Increased lumbar kyphosis & $\begin{array}{c}\text { Varying degree of thoracic } \\
\text { lordosis }\end{array}$ \\
\hline 4 & Lumbar kyphosis & Enlarged thoracic kyphosis \\
\hline
\end{tabular}

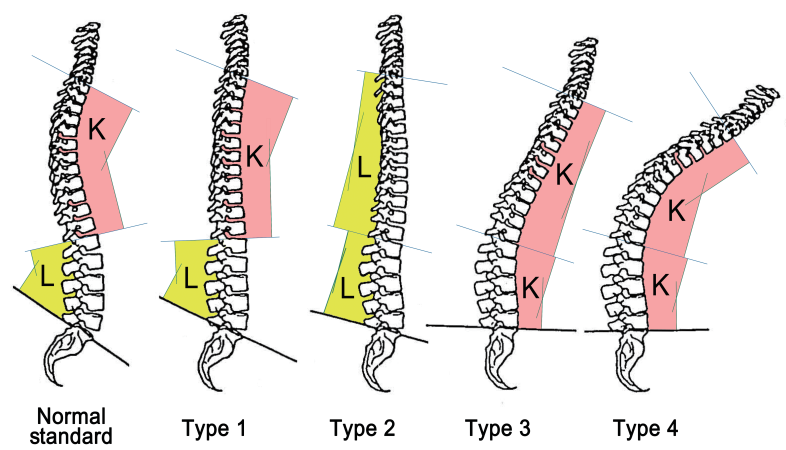

Fig. 2. Classification of the 4 types of 'LDK' with illustration of each type. These images were quoted from Takemitsu et al. ${ }^{23)}$. LDK : lumbar degenerative kyphosis. L: lordosis, K: kyphosis.

cludes only kyphosis in the spine. However, type 1 LDK includes "little lumbar lordosis". Moreover, keywords of the disease such as a female predilection, work in crouched posture, and extensor muscle atrophy are not included in the diagnostic criteria. Strictly speaking, the 'LDK' as named by Takemitsu et al. ${ }^{23)}$ is an agriculture-related disease of elderly Asian females, and this nomenclature needs to be changed to a more comprehensive term to prevent misunderstanding.

\section{New appropriate name of degenerative spinal disease with sagittal imbalance}

Adult sagittal plane spinal deformity is diagnosed in adult patients when it occurs or becomes relevant after skeletal maturity with loss of lumbar lordosis, and is divided into sagittal deformity unknown cause and secondary sagittal imbalance depending on the cause, as noted in Table $2^{2)}$. The sagittal deformity unknown cause is also divided into late onset $(\geq 60$ years of age) and adolescent onset deformities depending on age of onset ${ }^{24)}$. Instead of LDK, we suggest the name "primary degenerative sagittal imbalance" (PDSI), which includes degenerative sagittal misalignments of the whole spine of un-
Table 2. Subtypes of adult sagittal spinal deformities

\begin{tabular}{ll}
\hline Type & \multicolumn{1}{c}{ Description } \\
\hline Type I & Primary (de novo) degenerative sagittal imbalance \\
Type II & Adolescent idiopathic sagittal imbalance \\
Type III & Secondary sagittal imbalance \\
IIIA & Due to bone metabolism abnormalities \\
IIIB & Due to trauma \\
IIIC & Due to iatrogenic causes or post-fusion \\
IIID & Due to dysplasia and neuromuscular \\
\hline
\end{tabular}

known origin, and is associated with back muscle wasting. We propose the following diagnostic criteria for PDSI : 1) C7 sagittal vertical axis $\geq 5 \mathrm{~cm}, 2$ ) pelvic incidence - lumbar lordosis $\geq 15^{\circ}$, and 3) pelvic tilt $\geq 25^{\circ}$. Evaluation of the paraspinal musculature is also considered when assessing magnetic resonance images of the lumbar spine. Measurement of the crosssectional area, visual grading of fatty atrophy, and assessment of the fascia may help the physician and radiologist reach a more confident diagnosis for the patients with clinically suspected $\operatorname{PDSI}^{10)}$.

Previous studies called this syndrome of loss of lumbar lordosis or flat back "fixed sagittal imbalance (FSI)"1,4,5,26), degenerative sagittal imbalance ${ }^{4)}, \mathrm{LDK}^{23)}$, or "primary sagittal deformity"25). FSI as defined by Bridwell and colleagues was a syndrome in which the patient is unable to stand up erect without flexing the knees and hips, characterized by degenerative changes, and may refer to only a severe form of $\mathrm{PDSI}^{5,6)}$. Those classified as degenerative sagittal imbalance defined by Bridwell and colleagues were patients with previous surgeries for spinal stenosis and degenerative disc disease without any coexistent scoliosis or traumatic kyphosis ${ }^{4)}$. With regard to iatrogenic sagittal imbalance, Doherty ${ }^{7}$ first described a symptomatic fixed and forward inclination of the trunk due to loss of normal lumbar lordosis following posterior instrumented fusion surgery in 1973, and Moe and Denis ${ }^{18)}$ referred to this condition with the term "flat-back syndrome", as a variant clinical manifestation due to fixed sagittal imbalance resulting from iatrogenic loss of lumbar lordosis. We suggest the term degenerative sagittal imbalance subtype IIIC, to highlight the cause of sagittal imbalance.

\section{Treatment of PDSI}

Patients diagnosed with PDSI are usually elderly females 
showing lower lumbar multi-level disc and facet degeneration, poor bony quality, and atrophy and fatty degeneration of the psoas and paraspinal extensor muscles ${ }^{24}$. Therefore, conservative treatments such as exercise and physiotherapy including backpack wearing are recommended as first line treatment ${ }^{17}$. Surgical treatment of PDSI is considered in patients who complain of walking difficulty or have intractable pain in the lower back and both legs with severe sagittal imbalance (kyphotic deformity) not responding to conservative management ${ }^{14,16,17}$. Other surgical indications described in previous studies were 1) marked atrophy of the back musculature on radiographic examination, 2) no severe osteoporosis, and 3) a strong will to undergo surgical treatment ${ }^{14,15,22,23)}$.

Some authors described other surgical indications of PDSI which were quoted by Lee et al. ${ }^{14)}$ These include notable clinical features referred to as the "four cardinal signs", such as difficulty in walking due to forward stooping of trunk, inability to hold things in front of themselves, support with elbows in order to wash dishes or faces, and difficulty in climbing slopes $^{15,16)}$. However, the original paper ${ }^{14)}$ that they quoted reported that these were common cardinal symptoms rather than surgical indications, and the surgical indications described were age $\leq 65$ years, ability to work, no response to conservative management, no severe osteoporosis, and a strong desire to undergo surgical treatment.

There is a growing interest in the use of spinopelvic parameters to predict outcomes in patients with degenerative spinal diseases $^{13)}$. The measurement of radiographic pelvic and spinal parameters for sagittal balance analysis has gained importance in reconstructive surgery of the spine, particularly in degenerative spinal diseases ${ }^{13)}$. A clear understanding of the principles of sagittal balance is vital to achieve optimum outcomes when treating spinal disorders ${ }^{20)}$.

\section{CONCLUSION}

The LDK named by Takemitsu et al. ${ }^{23}$ is likely a female farmers' (occupational) spinal disease with sagittal imbalance. Using LDK as a synonym for all degenerative spinal diseases with sagittal imbalances had better be avoided. To avoid confusion, we recommend using PDSI as a new name with an accurate conception instead of LDK. Surgical treatment of PDSI is considered in patients with walking difficulty and intractable pain.

\section{- Acknowledgements}

This research was supported by a grant of the Korea Health Technology R\&D Project through the Korea Health Industry Development Institute (KHIDI), funded by the Ministry of Health \& Welfare, Republic of Korea (HC15C1288).

\section{References}

1. Acosta FL Jr, McClendon J Jr, O'Shaughnessy BA, Koller H, Neal CJ, Meier $\mathrm{O}$, et al. : Morbidity and mortality after spinal deformity surgery in patients 75 years and older : complications and predictive factors. J Neurosurg Spine 15 : 667-674, 2011

2. Bayerl SH, Pohlmann F, Finger T, Onken J, Franke J, Czabanka M, et al. : The sagittal balance does not influence the 1 year clinical outcome of patients with lumbar spinal stenosis without obvious instability after microsurgical decompression. Spine (Phila Pa 1976) 40 : 1014-1021, 2015

3. Blondel B, Schwab F, Bess S, Ames C, Mummaneni PV, Hart R, et al. : Posterior global malalignment after osteotomy for sagittal plane deformity : it happens and here is why. Spine (Phila Pa 1976) 38 : E394E401, 2013

4. Booth KC, Bridwell KH, Lenke LG, Baldus CR, Blanke KM : Complications and predictive factors for the successful treatment of flatback deformity (fixed sagittal imbalance). Spine (Phila Pa 1976) 24 : 1712-1720, 1999

5. Bridwell $K H$, Lenke LG, Lewis $\mathrm{SJ}$ : Treatment of spinal stenosis and fixed sagittal imbalance. Clin Orthop Relat Res (384) : 35-44, 2001

6. Bridwell KH, Lewis SJ, Lenke LG, Baldus C, Blanke K : Pedicle subtraction osteotomy for the treatment of fixed sagittal imbalance. J Bone Joint Surg Am 85-A : 454-463, 2003

7. Doherty JH : Complications of fusion in lumbar scoliosis. J Bone Joint Surg Am 55 : 438-449, 1973

8. Good CR, Auerbach JD, O'Leary PT, Schuler TC : Adult spine deformity. Curr Rev Musculoskelet Med 4 : 159-167, 2011

9. Jang JS, Lee SH, Min JH, Maeng DH : Influence of lumbar lordosis restoration on thoracic curve and sagittal position in lumbar degenerative kyphosis patients. Spine (Phila Pa 1976) 34 : 280-284, 2009

10. Kang CH, Shin MJ, Kim SM, Lee SH, Lee CS : MRI of paraspinal muscles in lumbar degenerative kyphosis patients and control patients with chronic low back pain. Clin Radiol 62 : 479-486, 2007

11. Kim KT, Lee SH, Suk KS, Lee JH, Im YS, Seo EM : Loss of sagittal balance and clinical outcomes following corrective osteotomy for lumbar degenerative kyphosis. J Korean Orthop Assoc 44 : 83-92, 2009

12. Kim WJ, Kang JW, Kang SI, Sung HI, Park KY, Park JG, et al. : Factors affecting clinical results after corrective osteotomy for lumbar degenerative kyphosis. Asian Spine J 4 : 7-14, 2010

13. Le Huec JC, Faundez A, Dominguez D, Hoffmeyer P, Aunoble S : Evidence showing the relationship between sagittal balance and clinical outcomes in surgical treatment of degenerative spinal diseases : a literature review. Int Orthop $39: 87-95,2015$ 
14. Lee CS, Lim YT, Kim E : Clinical study of lumbar degenerative kyphosis. J of Korean Spine Surg $4:$ 27-35, 1997

15. Lee JH, Kim KT, Lee SH, Kang KC, Oh HS, Kim YJ, et al. : Overcorrection of lumbar lordosis for adult spinal deformity with sagittal imbalance : comparison of radiographic outcomes between overcorrection and undercorrection. Eur Spine J 25 : 2668-2675, 2016

16. Lee SH, Kim KT, Suk KS, Lee JH, Seo EM, Huh DS : Sagittal decompensation after corrective osteotomy for lumbar degenerative kyphosis : classification and risk factors. Spine (Phila Pa 1976) 36 : E538-E544, 2011

17. Lee SS, Yoo JY, Rhim SC, Lee JW, Byun JH : Dynamic changes of pelvis and lower extremities after operation in lumbar degenerative kyphosis.

J Korean Acad Rehabil Med 30 : 57-61, 2006

18. Moe JH, Denis F : The iatrogenic loss of lumbar lordosis. Orthop Trans 1 : 131, 1977

19. Roussouly P, Gollogly S, Berthonnaud E, Dimnet J : Classification of the normal variation in the sagittal alignment of the human lumbar spine and pelvis in the standing position. Spine (Phila Pa 1976) 30 : 346353, 2005

20. Roussouly P, Nnadi C : Sagittal plane deformity : an overview of interpretation and management. Eur Spine J 19 : 1824-1836, 2010
21. Sparrey CJ, Bailey JF, Safaee M, Clark AJ, Lafage V, Schwab F, et al. : Etiology of lumbar lordosis and its pathophysiology : a review of the evolution of lumbar lordosis, and the mechanics and biology of lumbar degeneration. Neurosurg Focus 36 : E1, 2014

22. Takemitsu $Y$ : Low back pain originated from the spine and surrounding structures especially on the abnorrnal spinal posture (in Japanese). J Jpn Spine Surg Asso 4 : 327-339, 1993

23. Takemitsu Y, Harada Y, Iwahara T, Miyamoto M, Miyatake Y : Lumbar degenerative kyphosis. Clinical, radiological and epidemiological studies. Spine (Phila Pa 1976) 13 : 1317-1326, 1988

24. Taneichi $\mathrm{H}$ : Update on pathology and surgical treatment for adult spinal deformity. J Orthop Sci 21 : 116-123, 2016

25. Terran J, Schwab F, Shaffrey Cl, Smith JS, Devos P, Ames CP, et al. : The SRS-Schwab adult spinal deformity classification : assessment and clinical correlations based on a prospective operative and nonoperative cohort. Neurosurgery 73 : 559-568, 2013

26. Yagi M, Rahm M, Gaines R, Maziad A, Ross T, Kim HJ, et al. : Characterization and surgical outcomes of proximal junctional failure in surgically treated patients with adult spinal deformity. Spine (Phila Pa 1976) 39 : E607-E614, 2014 